\title{
Gamma Radiography Testing of Collimators for Boron Neutron Capture Therapy
}

\author{
Deo Clinton Maranatha Simangunsong ${ }^{1, *}$, Yohannes Sardjono ${ }^{2}$, Budi Setyahandana ${ }^{1}$, Sigit Santosa ${ }^{3}$, and \\ Fajar Nurjaman ${ }^{4}$ \\ ${ }^{1}$ Department of Mechanical Engineering, Faculty of Science and Technology, Sanata Dharma University, Paingan Maguwoharjo, Depok, \\ Sleman, Yogyakarta 55281, Indonesia \\ ${ }^{2}$ Center of Accelerator Science and Technology, National Nuclear Energy Agency, Yogyakarta 55281, Indonesia \\ ${ }^{3}$ Center of Nuclear Quality Standarization, National Nuclear Energy Agency of Indonesia, Serpong, South Tangerang City, Banten 15314, \\ Indonesia \\ ${ }^{4}$ Mineral Technology Research Center, Indonesian Institutes of Sciences, Southern Lampung District, Lampung 35361, Indonesia \\ *Corresponding author: deocms44@gmail.com
}

\author{
KEYWORDS \\ Iridium-192 \\ BNCT \\ Gamma radiography \\ BNCT collimator \\ Cracks \\ Porosity
}

\begin{abstract}
Boron neutron cancer therapy is a cancer treatment method that encompasses epithermal neutron irradiation of boron delivered to tumor cells. Using collimators, fast neutrons are moderated into epithermal neutrons. When radiation is performed, neutron beams are emitted and filtered by a collimator. In this study, 12 collimators used in the BNCT process were inspected for their quality, in terms of defects or flaws. The inspected collimators were manufactured by centrifugal casting and were composed of $99 \%$ pure nickel. They had the following dimensions: height of $145 \mathrm{~mm}$, outer diameter of $190 \mathrm{~mm}$, inner diameter of $160 \mathrm{~mm}$, and thickness of $15 \mathrm{~mm}$. The inspection method used was gamma radiography testing with an Iridium-192 gamma source. Using a single wall single image technique, the collimators were exposed for 30 seconds. Six FUJI films were placed behind the object to record the resulting images, which showed light or dark areas on each collimator, the latter of which indicated porosity or flaws. Based on these images, collimators 1 and 5 were found to contain cracks, and porosity was identified in almost all of the collimators. It is suggested that both collimators with cracks be recycled, while the collimators with porosities should be investigated further to determine their suitability for boron neutron cancer therapy.
\end{abstract}

(c) The Author(s) 2019. This article is distributed under a Creative Commons Attribution-ShareAlike 4.0 International license

\section{INTRODUCTION}

Cancer is one of the world's biggest problems (Sarfati et al. 2018). According to the National Cancer Institute, 14.1 million new cases of cancer occurred in 2012, with 8.2 million cancer-related deaths worldwide. By 2030, the yearly number of new cancer cases is expected to rise to 23.6 million. The second-leading cause of mortality, cancer occurs when human cells mutate and undergo abnormal and unregulated growth (Hassanpour and Dehghani 2017). These mutations change cell functions and damage genes. Cancer can be caused by carcinogens, radiation, viruses, as well as inherited faulty genes. Most carcinogens damage the DNA, leading to the abnormal growth of cells (Sudhakar 2009).

Initially, surgery encompassed the majority of cancer treatment modalities. By the end of the $19^{\text {th }}$ century, however, the Billroth technique for stomach cancer and the Halsted technique for breast cancer were already in use. In 1902, radium was discovered, initiating the use of ionizing radiation for cancer treatment. Cancer therapy continuously expanded based on the availability of chemotherapy in the mid $20^{\text {th }}$ century. These three anticancer modalities were later combined. Surgery, radiotherapy, chemotherapy, or their combination were used for cancer intervention focused on diagnosis and treatment (Lage and Romero 2018). Other strategies to fight cancer started to appear, such as uterine cervix cytology for the pre-clinical diagnosis of cancer, proposed by G. Papanicolau in 1923, which increased the use of Pap tests in the 1950s. Later, its widespread use started to show evidence that it could reduce mortality. In the late 1960s, mammographies were introduced for the early diagnosis of breast cancer, and later on, fecal occult blood tests were proposed for colorectal cancer (Bilalodin et al. 2017). Several epidemiological studies in the 1950s established the relationship between tobacco smoking and lung cancer, and resulted in the estimation that the reduction of mortality was achievable by the cessation of tobacco use.

In Indonesia, traditional herbal medicine known as jamu has been used for a variety of ailments, with plants from the Zingiberaceae family being the most frequently used as ingredients. Eleven Curcuma species from this family, namely C. aeruginosa, C. aurantiaca, C. colorata, C. longa (also known as C. domestica), C. euchroma, C. mangga, C. petiolata, C. purpurascens, C. soloensis, C. xanthorrhizae, and C. zedoria have been used both as a spice and to treat several illnesses including appendicitis, asthma, itching, rheumatism, abdominalgia, anemia, hypertension, diarrhea, and dysentery. Recent investigations show that $C$. longa has promising effects in this area, mainly due to the presence of curcumin. Several studies suggest that curcumin has potential in the prevention and treatment of can- 
cer. That said, C. longa has not traditionally been used for anti-carcinogenic purposes (Elfahmi et al. 2014).

Another cancer treatment option is boron neutron capture therapy (BNCT), which involves the selective delivery of boron to cancerous tissue, followed by irradiation with epithermal neutrons (Maitz et al. 2017). When irradiated with low-energy neutrons (b0.4 eV), ${ }^{10} \mathrm{~B}$, the isotope of boron (which is delivered beforehand by drugs or antibodies that then flow through blood vessels), captures the neutron and forms ${ }^{11} \mathrm{~B}$. It then undergoes a nuclear reaction that results in the release of an alpha particle and a lithium nucleus, as shown in Equation 1(Nedunchezhian et al. 2016).

$$
{ }^{10} \mathrm{~B}+n \rightarrow{ }^{7} \mathrm{Li}+{ }^{4} \mathrm{He}
$$

These particles have a high linear energy transfer and short track lengths $(5-9 \mu \mathrm{m})$, resulting in a significant radiation killing effect in an area roughly equivalent to one cell diameter. In general, it is intended that the boron delivery agents, as well as the low energy neutron beam, have very little biologic effect by themselves. Boron is used for BNCT due to its high cross section (3840 barns) for thermal neutron capture and is not toxic. The delivered boron are highly absorbed by tumor cells, because the tumor cells' metabolism is faster than that of healthy cells (Brandão and Campos 2009).

The neutrons that are used for BNCT come from a neutron source. This neutron source can be in the form of a cyclotron, linear accelerator, nuclear reactor, or neutron generator. The neutron source produces a neutron flux. However, the neutron flux produced from these sources does not meet the requirements necessary to be used in BNCT, as the neutrons are fast neutrons. This is due to the fact that for cancer cells located inside the human skin (around 8-10 $\mathrm{cm}$ beyond the skin), BNCT requires irradiation via epithermal neutrons, which can be moderated through human skin and become thermal neutrons. Based on the International Atomic Energy Agency's (IAEA) criteria, the desired epithermal neutron flux for BNCT is $10^{9}$ neutrons $\mathrm{cm}^{-2} \mathrm{~s}^{-1}$.

Beam quality is determined by four parameters: the fast neutron component, the gamma ray component, the ratio between the thermal flux and epithermal flux, and the ratio between the total neutron current and the total neutron flux. The target gamma ray component should be $2 \times$ $10^{-13} \mathrm{~Gy} \mathrm{~cm}^{2}$ per epithermal neutron. The range in existing facilities is from 1 to $13 \times 10^{-13} \mathrm{~Gy} \mathrm{~cm}^{2}$ per epithermal neutron. Meanwhile, the ratio of thermal flux and epithermal flux should be 0.05 . A high ratio between the total neutron current and the total neutron is preferred. This high ratio is important to limiting the separation of the neutron beam and reducing undesired irradiation, as well as to allow flexibility of patient positioning along the beam's central axis. The target number for this ratio is above 0.7 (International Atomic Energy Agency 2001).

To fulfill the IAEA's parameters above and produce a good quality neutron beam, many kinds of beam shaping assembly are proposed. Beam shaping assemblies are designed to moderate the fast neutron which comes out from neutron source (Fantidis and Nicolaou 2018). Generally, they consist of a moderator, reflector, thermal neutron filter, gamma filter, and collimator (Bavarnegin et al. 2017). A neutron collimator will collimate the neutrons produced from the source. Thus, a collimator used for BNCT must meet the required conditions. Collimators are produced through centrifugal casting, which is a casting method us- ing centrifugal force and a rotating mold. Nickel is heated to its melting point, producing the molten nickel that is used for casting. This molten nickel is poured into the mold, and then rotated with a high speed. Due to the high rotation speed of the mold, a strong centrifugal force occurs, forcing the material around the inner mold and forming a round contour (Ebhota et al. 2016). Gravity casting is also proposed as one of the BNCT collimator manufacture methods, but it believed to have such disadvantages and defect potential (Nurhadiyanto et al. 2017). For effective treatment, collimators must be free from any defects or flaws (Mujiyono et al. 2018). Furthermore, an optimum collimator should be produced to deliver an epithermal neutron beam within a reasonable treatment time and to produce the desired thermal neutrons (Warfi et al. 2016).

The collimator is required to obtain an appropriate epithermal neutron of IAEA standard (Payudan et al. 2016). It is inspected for its quality before being used for BNCT. The reflector will be inspected for any hidden flaws, defects, cracks, or porosities. Radiography testing is conducted for the inspection. Radiography testing is a nondestructive test (Mgonja 2017). A non-destructive test will spot the flaws or defects inside the object without harming or damaging it (Dwivedi et al. 2018). Radiography testing is one of the non-destructive tests that use radiation to penetrate through the inspected object. The radiation will be absorbed by material, and show the defect inside it (Lopez et al. 2018). However, radiography testing requires an experienced and professional radiographer. This is due to the difficulty and complexity of the non-destructive test results, which necessitate experience in their analysis and interpretation. Still, errors or mistakes may possibly occur when performing this inspection or interpreting the results (Verma et al. 2013).

Compared with other testing methods, radiography testing is the most common. Basically, the object to be inspected will determine what kind of radiography testing will be performed. The thickness of the object also plays a role in this case. Low voltage radiography is enough to inspect thinner objects (1-5 mm in thickness). Otherwise, gamma radiography can be used for thicker objects because of its short wavelength (Gholizadeh 2016). X-rays and gamma-rays are forms of electromagnetic radiation. Both of these type of radiation testing are used in radiography testing or industrial radiography (Yilmaz et al. 2018).

When conducting gamma radiography testing, gamma rays are emitted and passed through the object. The results of this test can be obtained by placing a film behind the ob-

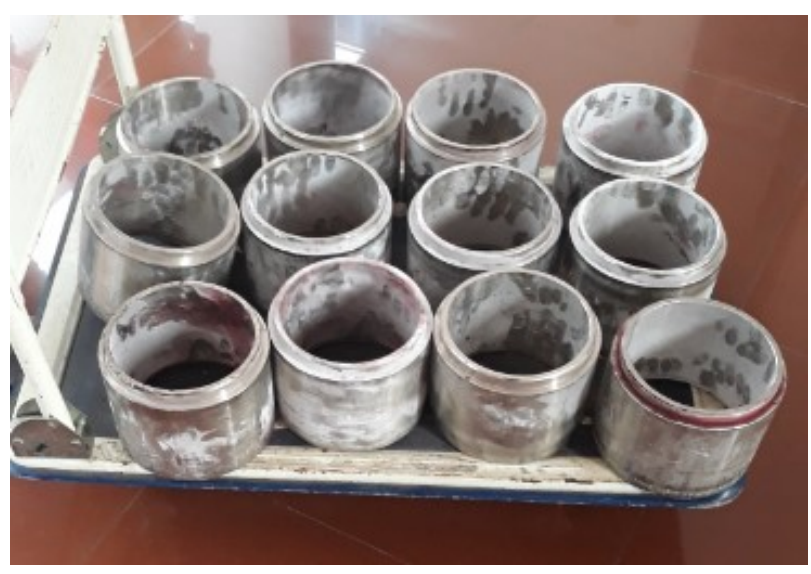

FIGURE 1. Collimators used in BNCT. 
ject. The gamma radiography testing results then reveal a variation of dark and bright colors on the film, which are caused by the gamma rays interacting with object materials while passing through. Thicker objects result in a brighter area on the film, while thinner objects result in a darker area (International Atomic Energy Agency 1996). Moreover, when gamma rays are emitted through a part that does not differ in thickness, and the resulting image shows a variation in darkness and lightness, it is possible to conclude that the part has been damaged. The flaws must be located inside the part, as nothing is spotted on the surface of the object.

There are many types of flaws that could be found using radiography inspection. In this study, cracks and porosities were the most common defects found. Cracks appear as straight or irregular darker lines, while dark spots with round and irregular contours refer to a porosity or gas cavity (Ben Gharsallah and Ben Braiek 2015).

\section{MATERIALS AND METHODS}

\subsection{BNCT collimators}

The objects inspected for this study were the reflectors of collimators. Twelve reflectors were produced by centrifugal casting using 99\% pure nickel as the material. The collimators were $145 \mathrm{~mm}$ in height, $190 \mathrm{~mm}$ in outer diameter, and with a thickness of $15 \mathrm{~mm}$. In order to obtain the reflectors' subsurface structure, gamma radiography testing was performed. Figure 1 shows the 12 collimators that were inspected using radiography testing.

\subsection{Gamma radiography testing}

In this study, collimators were inspected using gamma radiography testing. Ir-192 (Iridium) was used as the gamma source for gamma radiography. Gamma rays were emitted, passing through the collimator before being received

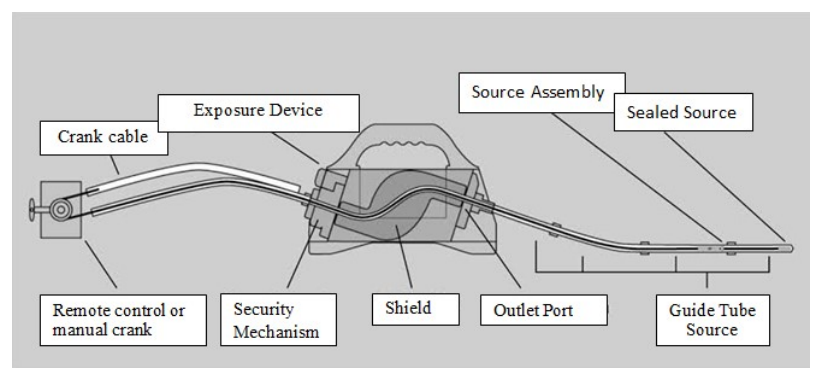

FIGURE 2. Exposure device used in gamma radiography testing.

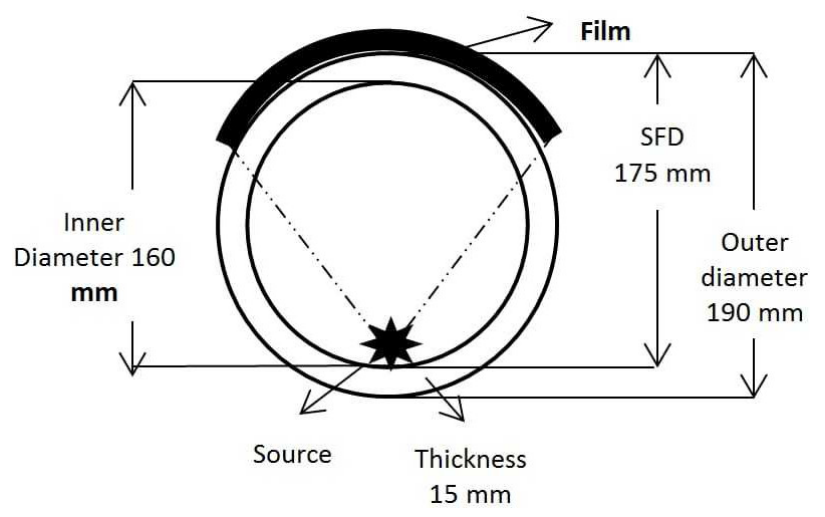

by film that was placed behind the collimator. Then the exposed film underwent a washing procedure in a darkroom before the resulting radiographs were viewed.

The gamma source was very tiny and therefore placed inside a capsule. This capsule was attached to a short and flexible cable called a pigtail. The source and pigtail were housed in a shielding device referred to as an exposure device. To start the exposure, a guide tube was placed on the reflector. The guide tube was attached to a crank cable, and it emitted gamma rays from the source. Once all preparations were complete, the source was quickly cranked out to start the exposure. At the end of the exposure, the source was quickly cranked back into the exposure device. Figure 2 shows the exposure device used in this study.

The exposed films cannot be read until they go through film processing. Once the film processing is complete, the films are dried before the radiograph is able to be viewed.

\subsection{Gamma radiography technique}

According to the American Society of Mechanical Engineers (2013) section V, exposure technique generally divided into single wall technique and double wall technique. As for double wall technique also divided into double wall single image and double wall double image. This experiment used a single wall single image technique (Figure 3), which means that the radiation passes through only one wall of material. The guide tube was placed on the inner side of the reflector, and facing the film that was placed on the outer side of the reflector. Using this technique, the value of the actual source to film distance (SFD) was $175 \mathrm{~mm}$.

\subsection{Calculating exposure time}

The exposure time was calculated using Equation 2.

$$
t=\left(\frac{S D F_{\text {actual }}}{S D F_{\text {curve }}}\right)^{2} \times \frac{E}{A}
$$

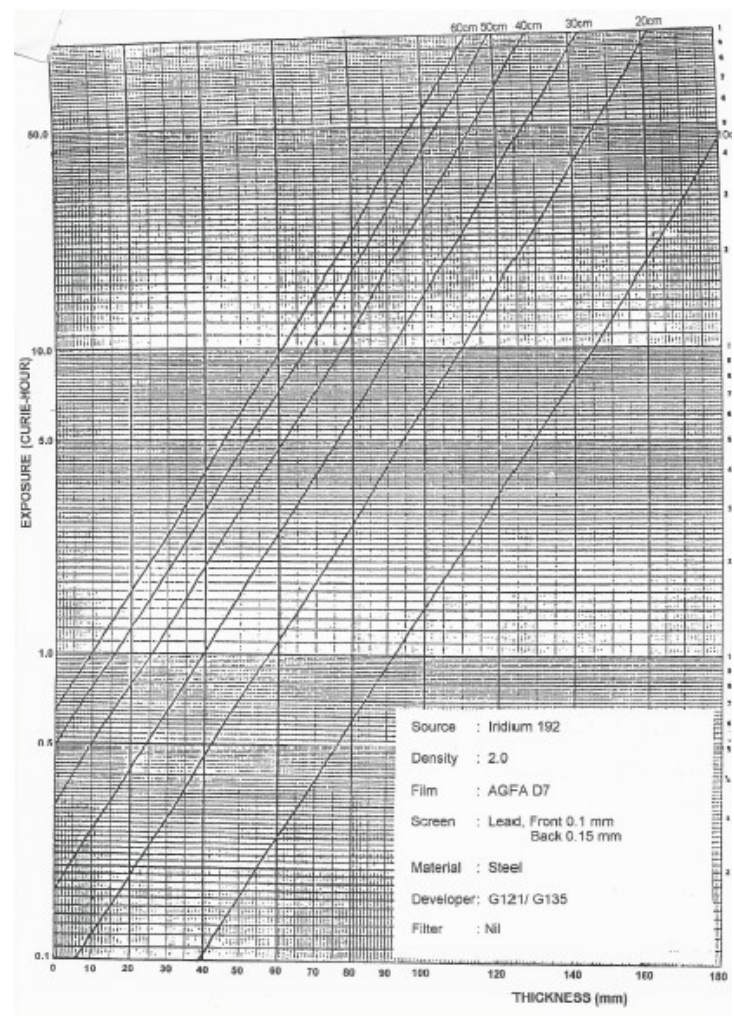


where $t$ is the calculated exposure time (in minutes), SFD $_{\text {actual }}$ is the actual distance of the gamma source to the film (mm), SFD curve is the standard SFD given based on the exposure chart used (mm), $\mathrm{E}$ is the exposure rate ( $\mathrm{Ci} \mathrm{min}$ ), and $\mathrm{A}$ is the source activity (Ci).

The value of the exposure rate was obtained from an exposure chart, which showed the relationship between exposure and thickness (Figure 4). The reflectors had a thickness of $15 \mathrm{~mm}$ and the SFD actual value for the Ir-192 gamma source was $610 \mathrm{~mm}$. The exposure chart uses centimeters for thickness and SFD dimensions, so some conversion from millimeters to centimeters is needed. As for $\mathrm{SFD}_{\text {actual }}$, this is determined by measuring the distance of the gamma source to the film. Using the single wall single image technique, a sealed source is set on the inner surface of the collimator while the film is placed on the outer surface of the collimator. The distance of the gamma source to the film is equal to the inner diameter of the reflector and its thickness; thus, $175 \mathrm{~mm}$ was the $\mathrm{SFD}_{\text {curve }}$ value. Equation 3 was used to calculate the exposure time.

$$
\begin{aligned}
t & =\left(\frac{175 \mathrm{~mm}}{610 \mathrm{~mm}}\right)^{2} \times \frac{110 \mathrm{Ci} \mathrm{min}}{14 \mathrm{Ci}} \\
t & =0.0823 \times 7.857 \mathrm{~min} \\
t & =0.6466 \text { minutes } \\
t & =38.8 \text { seconds }
\end{aligned}
$$

Theoretically, the collimator should be exposed for 38.8 seconds. In reality, the first exposure lasted around $30 \mathrm{sec}-$ onds and resulted in an overexposed film. Through trial and error, a test of the exposure time was performed. Some exposures under different exposure times were tested and the quality of the exposed film was evaluated. An exposure time of around 27 seconds came out as the appropriate time

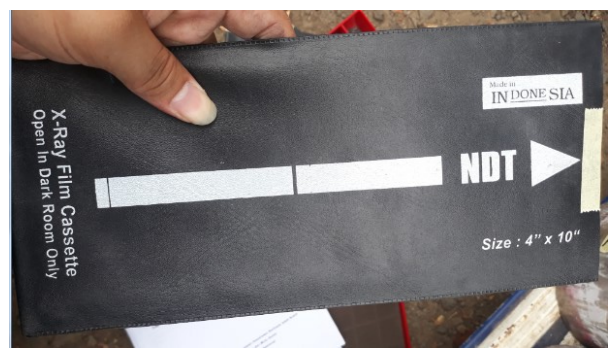

FIGURE 5. FUJI film used in gamma radiography testing.

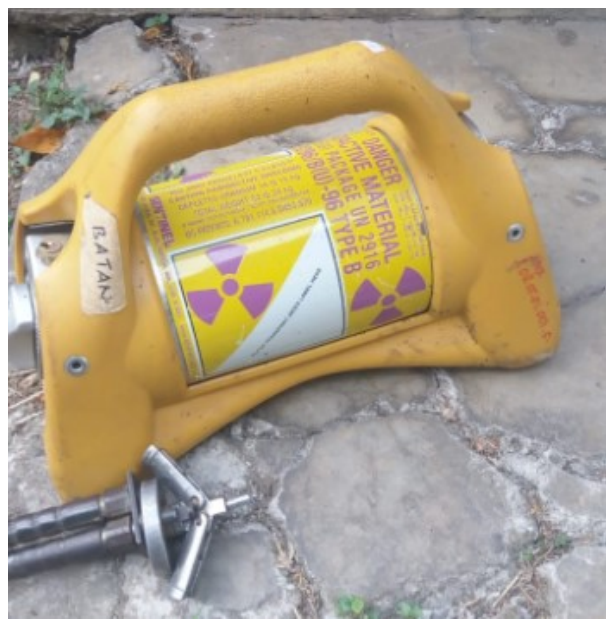

FIGURE 6. Exposure device package UN 2916 9296/B(U) - 96 TYPE B. to obtain some good quality radiographs.

In this experiment, FUJI film with a 4 inch $\times 10$ inch $(101.6 \mathrm{~mm} \times 254 \mathrm{~mm})$ dimension was used (Figure 5).

\subsection{Gamma Radiography Equipment}

This experiment used an Ir-192 gamma source with a $14 \mathrm{Ci}$ source activity. The exposure device used in this research is shown in Figure 6.

\section{RESULTS AND DISCUSSION}

The structure of collimators' subsurface was assessed using gamma radiography testing. Based on the obtained radiographs, cracks were found in collimators number 01 and 05. Furthermore, porosities were found in almost all of the collimators. Figure 7 shows the radiography results of some of the collimators, where a red circle with an arrow indicates a crack and a lone red circle indicates porosities. As the film shows, a crack was found inside collimator 01, part 1-2, side A. A crack and a number of porosities were found in collimator 05 , part 1-2, side B, while porosities were also found in part 2-0, side A. Meanwhile, gamma radiography revealed collimator 12, part 0-1, side B and collimator 11, part 0-1, side B to contain porosities.

Tables 1 and 2 show the result of data analysis and interpretation of collimators 01 and 05 . As they show, the crack in collimator 01, part 1-2, side A had an $8 \mathrm{~cm}$ crack, located
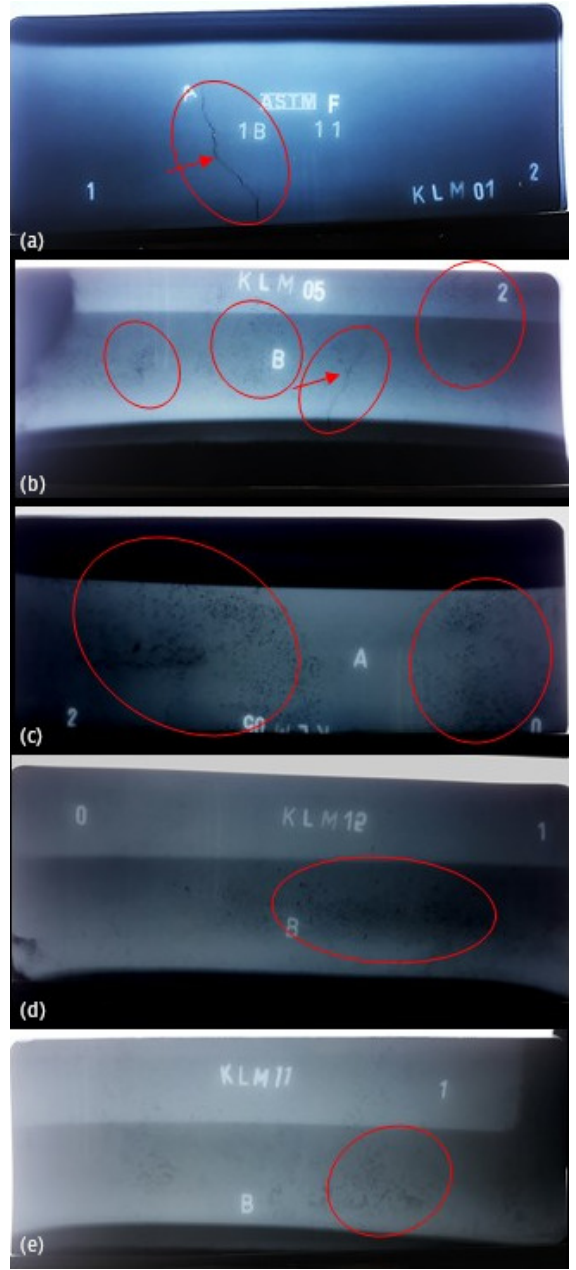

FIGURE 7. Gamma radiography results of some of the collimators. (a) Collimator 01 , part 1-2, side A; (b) collimator 05 , part 1-2, side B; (c) collimator 05 , part 2-0, side $A$; (d) collimator 12 , part $0-1$, side $B$; (e) collimator 11 , part $0-1$, side $B$. Cracks are indicated with an arrow and red circle, while porosities are only circled. 
TABLE 1. Interpretation and data analysis of collimator 01.

\begin{tabular}{|c|c|c|c|c|c|c|c|}
\hline \multirow[t]{3}{*}{ Part } & \multirow[t]{3}{*}{ Side } & \multicolumn{5}{|c|}{ Defect } & \multirow[t]{3}{*}{ Status } \\
\hline & & \multicolumn{2}{|c|}{ Defect type } & \multirow[t]{2}{*}{ Characteristic } & \multirow[t]{2}{*}{ Location } & \multirow[t]{2}{*}{ Size } & \\
\hline & & Porosity & Crack & & & & \\
\hline \multirow[t]{2}{*}{$0-1$} & $A$ & $\sqrt{ }$ & $\sqrt{ }$ & Singular porosity, transversal crack & Porosity: $14 \mathrm{~cm}$; crack: $15 \mathrm{~cm}$ & Crack: $2 \mathrm{~cm}$ & Defect \\
\hline & B & & $\sqrt{ }$ & Transversal crack & Crack: $15-18 \mathrm{~cm}$ & Crack: $8 \mathrm{~cm}$ & Defect \\
\hline \multirow[t]{2}{*}{$1-2$} & A & & $\sqrt{ }$ & Transversal crack & Crack: $5-7 \mathrm{~cm}$ & Crack: $8 \mathrm{~cm}$ & Defect \\
\hline & $\mathrm{B}$ & $\sqrt{ }$ & $\sqrt{ }$ & Porosity, transversal crack & Porosity: $7-8 \mathrm{~cm}$; Crack: $5-7 \mathrm{~cm}$ & $\begin{array}{l}\text { Porosity diameter: } 0.5 \mathrm{~cm} \text {; } \\
\text { crack: } 4 \mathrm{~cm}\end{array}$ & Defect \\
\hline \multirow[t]{2}{*}{$2-0$} & $A$ & $\sqrt{ }$ & & Singular Porosity & Porosity: $1 \mathrm{~cm}$ & Porosity diameter: $0.2 \mathrm{~cm}$ & Defect \\
\hline & $\mathrm{B}$ & & $\sqrt{ }$ & Transversal crack & Crack: $11-13 \mathrm{~cm}$ & Crack: $6 \mathrm{~cm}$ & Defect \\
\hline
\end{tabular}

TABLE 2. Interpretation and data analysis of collimator 05 .

\begin{tabular}{|c|c|c|c|c|c|c|c|}
\hline \multirow[t]{3}{*}{ Part } & \multirow[t]{3}{*}{ Side } & \multicolumn{5}{|c|}{ Defect } & \multirow[t]{3}{*}{ Status } \\
\hline & & \multicolumn{2}{|c|}{ Defect type } & \multirow[t]{2}{*}{ Characteristic } & \multirow[t]{2}{*}{ Location } & \multirow[t]{2}{*}{ Size } & \\
\hline & & Porosity & Crack & & & & \\
\hline \multirow[t]{2}{*}{$0-1$} & A & $\sqrt{ }$ & $\sqrt{ }$ & High porosity, crack & Crack: $10 \mathrm{~cm}$ & Crack: $2 \mathrm{~cm}$ & Defect \\
\hline & B & $\sqrt{ }$ & & High porosity & Full porosity & & Defect \\
\hline \multirow[t]{2}{*}{$1-2$} & A & $\sqrt{ }$ & & High porosity & Full porosity & & Defect \\
\hline & B & $\sqrt{ }$ & $\sqrt{ }$ & High porosity, transversal crack & Crack: $12-13 \mathrm{~cm}$ & Crack: $5.5 \mathrm{~cm}$ & Defect \\
\hline \multirow[t]{2}{*}{$2-0$} & A & $\sqrt{ }$ & & High porosity & Full porosity & Porosity diameter: $0.2 \mathrm{~cm}$ & Defect \\
\hline & B & $\sqrt{ }$ & & High porosity & Full porosity & Crack: $6 \mathrm{~cm}$ & Defect \\
\hline
\end{tabular}

5-7 $\mathrm{cm}$ from the number one sign on the left side of the film. Crack and porosity locations on the collimator could thus be found using these data. Meanwhile, collimator 05, part 1-2, side B contained a crack $5.5 \mathrm{~cm}$ in length, located $12-13 \mathrm{~cm}$ from the number one sign on the left side of the film. A high number of porosities were found in the collimator. Among the 12 collimators, collimator 10 was found to be the least flawed.

\section{CONCLUSIONS}

This study aimed to determine the structure of collimators' subsurface, as high quality collimators are needed to collimate neutron beams effectively. The presence of cracks or porosities thus necessitates either recycling the affected collimators or ensuring their ability to produce qualified neutron beams.

Based on the results of gamma radiography testing, it can be concluded that all of the collimators in this study had defects. Cracks were spotted in collimators 01 and 05, while porosities were found in almost all of the collimators. The collimators with the fewest flaws were 08 and 10. There are several reasons that explain the appearance of these cracks and porosities, such as the production method. Nonetheless, based on the standard required for collimators used in BNCT, those that contain cracks, such as collimators 01 and 05 , cannot be accepted and need to be renewed. Other collimators that only have porosities should undergo further investigation to determine their suitability for BNCT.

\section{ACKNOWLEDGMENTS}

We sincerely thank PSTA and PSMN BATAN for providing the facilities needed for this study and to all staff members who helped carry out this research.

\section{REFERENCES}

American Society of Mechanical Engineers. 2013. ASME boiler and pressure vessel committee on nondestructive examination. New York: American Society of Mechanical Engineers.

Bavarnegin E, Kasesaz Y, Wagner FM. 2017. Neutron beams implemented at nuclear research reactors for bnct. J Instrum. 12(5):P05005. doi:10.1088/1748-0221/12/05/ P0500.

Ben Gharsallah M, Ben Braiek E. 2015. Weld inspection based on radiography image segmentation with level set active contour guided off-center saliency map. Adv Mater Sci Eng. 2015:1-10. doi:10.1155/2015/871602.

Bilalodin, Kusminarto, Hermanto A, Sardjono Y, Sunardi. 2017. Double layer collimator for BNCT neutron source based on $30 \mathrm{MeV}$ cyclotron. Indones J Phys Nucl Appl. 2(3):124. doi:10.24246/ijpna.v2i3.124-127.

Brandão SF, Campos TPR. 2009. Dosimetric analysis of BNCT - boron neutron capture therapy - coupled to ${ }^{252}$ cf brachytheraphy. Paper presented at: 2009 International Nuclear Atlantic Conference; Rio de Janeiro, Brazil.

Dwivedi SK, Vishwakarma M, Soni A. 2018. Advances and researches on non destructive testing: A review. Mater Today: Proc. 5(2):3690-3698. doi:10.1016/j.matpr.2017 .11 .620 .

Ebhota WS, Karun AS, Inambao FL. 2016. Centrifugal casting technique baseline knowledge, applications, and processing parameters: overview. Int J Mater Res. 107(10):960-969. doi:10.3139/146.111423.

Elfahmi NV, Woerdenbag HJ, Kayser O. 2014. Jamu: Indonesian traditional herbal medicine towards rational phytopharmacological use. J Herb Med. 4(2):51-73. doi: 10.1016/j.hermed.2014.01.002.

Fantidis JG, Nicolaou G. 2018. Optimization of beam shap- 
ing assembly design for boron neutron capture therapy based on a transportable proton accelerator. Alexandria Eng J. 57(4):2333-2342. doi:10.1016/j.aej.2017.08.00 4.

Gholizadeh S. 2016. A review of non-destructive testing methods of composite materials. Procedia Struct Integr. 1:50-57. doi:10.1016/J.PROSTR.2016.02.008.

Hassanpour SH, Dehghani M. 2017. Review of cancer from perspective of molecular. J Cancer Res Pract. 4(4):127129. doi:10.1016/J.JCRPR.2017.07.001.

International Atomic Energy Agency. 1996. Manual on gamma radiography. Vienna: International Atomic Energy Agency. https://gnssn.iaea.org/CSN/TM\%2048 337\%20Industrial\%20Radiography/Reference\%20Mat erial/IAEA\%20Practical\%20Radiation\%20Safety\%20 Manual\%20on\%20Gamma\%20Radiography.pdf.

International Atomic Energy Agency. 2001. Current status of neutron capture therapy. Vienna: International Atomic Energy Agency. https://pub.iaea.org/MTCD/ Publications/PDF/te_1223_prn.pdf.

Lage A, Romero T. 2018. Back and forth between cancer treatment and cancer control programs: insights from the Cuban experience. Semin Oncol. 45(1-2):12-17. doi: 10.1053/J.SEMINONCOL.2018.04.004.

Lopez A, Bacelar R, Pires I, Santos TG, Sousa JP, Quintino L. 2018. Non-destructive testing application of radiography and ultrasound for wire and arc additive manufacturing. Addit Manuf. 21:298-306. doi:10.1016/j.addma. 2018.03.020.

Maitz CA, Khan AA, Kueffer PJ, Brockman JD, Dixson J, Jalisatgi SS, Nigg DW, Everett TA, Hawthorne MF. 2017. Validation and comparison of the therapeutic efficacy of boron neutron capture therapy mediated by boron-rich liposomes in multiple murine tumor models. Transl Oncol. 10(4):686-692. doi:10.1016/j.tranon.2 017.05.003.

Mgonja CT. 2017. Evaluation on use of industrial radiography for weld joints inspection in Tanzania. Int J Mech Eng Technol. 8(5):65-74.

Mujiyono, Suharto, Mukhammad AFH, Nurhadiyanto D, Sumowidagdo AL. 2018. Manufacture of nickel colli- mator for BNCT: smelting of nickel using electrical arc furnace and centrifugal casting preparation. Indones J Phys Nucl Appl. 3(1):21-28. doi:10.24246/ijpna.v3i1.21-2 8.

Nedunchezhian K, Aswath N, Thiruppathy M, Thirugnanamurthy S. 2016. Boron neutron capture therapy - a literature review. J Clin Diagn Res. 10(12):1-4. doi: 10.7860/JCDR/2016/19890.9024.

Nurhadiyanto D, Mujiyono, Ristadi FA. 2017. The characteristics of aluminum casting product using centrifugal casting machine. International Conference on Technology and Vocational Teachers (ICTVT 2017). Paris: Atlantis Press. p. 153-158. doi:10.2991/ictvt-17.2017.27.

Payudan A, Aziz AN, Sardjono Y. 2016. Basic principle application and technology of boron neutron capture cancer therapy (BNCT) utilizing Monte Carlo N Particle 5's software (MCNP 5) with compact neutron generator (CNG). Indones J Phys Nucl Appl. 1(1):20. doi: 10.24246/ijpna.v1i1.20-33.

Sarfati D, Garvey G, Robson B, Moore S, Cunningham R, Withrow D, Griffiths K, Caron NR, Bray F. 2018. Measuring cancer in indigenous populations. Ann Epidemiol. 28(5):335-342. doi:10.1016/J.ANNEPIDEM.2018.02.005.

Sudhakar A. 2009. History of cancer, ancient and modern treatment methods. J Cancer Sci Ther. 01(02):i-iv. doi: 10.4172/1948-5956.100000e2.

Verma SK, Bhadauria SS, Akhtar S. 2013. Review of nondestructive testing methods for condition monitoring of concrete structures. J Constr Eng. 2013:1-11. doi: 10.1155/2013/834572.

Warfi R, Harto AW, Sardjono Y, Widarto W. 2016. Optimization of neutron collimator in the thermal column of Kartini Research Reactor for in vitro and in vivo trials facility of boron neutron capture therapy using MCNP-X simulator. Indones J Phys Nucl Appl. 1(1):54. doi:10.24246/ijpna.vli1.54-62.

Yilmaz D, Güzeldir B, Akkuş T, Öznülüer T. 2018. X- and gamma-ray irradiation effects on vanadium pentoxide thin films. Spectrosc Lett. 51(6):297-301. doi:10.1080/ 00387010.2018.1475397. 